\title{
Fin de vie
}

\section{Erhard Taverna}

Dr med., membre de la rédaction

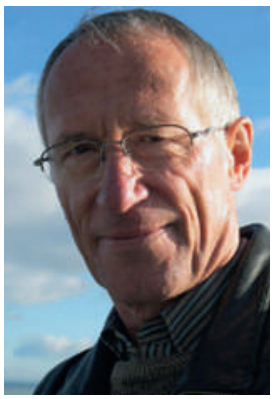

Dans notre Etat, chacun a un droit inaliénable à ses convictions éthiques personnelles, qui est le fruit d'acquis comme la liberté de culte, de réunion et d'expression. Quiconque est dégoûté de la vie, quelles qu'en soient les raisons, doit pouvoir décider en toute autonomie comment il souhaite quitter ce bas monde. Aucun médecin, politicien, juriste ou théologien, ni aucune majorité de votants ne peuvent restreindre ou nier ce droit fondamental de l'individu à l'autodétermination. Ils ne peuvent décider que pour eux-mêmes, jamais pour les autres.

La composition par âge de la population, et avec elle l'épidémiologie médicale, ont connu des changements sans précédent. Et les progrès de la médecine moderne, justement, ont créé des chances et des risques insoupçonnés jusqu'alors. On peut aujourd'hui réaliser des interventions intra-utérines, faire survivre les grands prématurés, sauver les blessés graves et prolonger la vie grâce à la réanimation et aux transplantations; des techniques de laboratoire rendent possible la procréation assistée, le cancer est traité comme une maladie chronique dans les meilleurs cas et les méthodes génétiques ouvrent la voie à des options qui donnent le vertige. Dans une société éclairée, ces techniques sont aussi l'objet de controverses, car la survie a un prix que chacun pondère différemment. Les directives anticipées du patient, qui sont aujourd'hui la règle, sont à l'image du choix toujours plus grand de possibilités qu'on lui offre. Ce que les uns glorifient comme un acquis inconditionnel suscite craintes ou opposition chez d'autres. Des médecins à l'esprit paternaliste ressentent peut-être ces directives comme une marque de perte de confiance, seuls les experts qu'ils sont pouvant à leurs yeux décider. Pour d'autres, cette expression de la volonté est une manifestation d'autonomie du patient, qui leur dit «jusque là et pas plus loin».

Il n'est pas interdit de sauter d'un pont, de se pendre ou de se tirer une balle dans le crâne. Qu'une personne âgée choisisse une manière plus douce de mettre fin à ses jours en prenant un barbiturique, beaucoup ont de la peine à l'accepter pour plusieurs raisons. Pourtant, personne ne fait ce choix à la légère. Il est donc cynique de vouloir définir un degré minimum de désespérance, mesuré en intensité des douleurs ou en temps de survie, pour l'autoriser. Mais l'interdiction a pour beaucoup d'énormes attraits. Une religion des lois qui impose sa conception du pouvoir réglemente tout, de la procréation à la mort. On attend même des non-croyants qu'ils s'y conforment. L'Etat séculaire accepte une utilisation très large de la médecine reproductive, mais peine à admettre le choix autodéterminé du suicide. Les raisons sont multiples: il est difficile de renoncer à une attitude excessivement protectrice, tant sont justifiées les craintes d'abus tels qu'une manipulation par des membres de la famille. On prête ainsi aux citoyennes et citoyens un manque de capacité de discernement, sans parler de la suspicion que peut susciter toute institution privée dans les sphères administrées par l'Etat. La fin de vie et la mort ne sont pas des sujets mobilisateurs dans notre société de consommation. Tous les efforts de la recherche, de la prévention et de la prise en charge thérapeutique visent à prolonger au maximum une vie aussi agréable que possible. L'assistance au suicide est inacceptable dans un quartier d'habitation, elle est au mieux tolérée sur les parkings et sites industriels. Dans des pays comme l'Allemagne, ce sont les antécédents criminels des aïeux et la forte influence de l'Eglise qui empêchent un traitement libéral du dossier par le Parlement.

Le développement de la médecine palliative est une nécessité, tout comme l'est l'assistance au suicide. Jouer l'une contre l'autre est une erreur. La médecine gériatrique est un marché juteux. Des arguments rationnels en apparence cachent souvent des luttes d'influence et d'énormes sommes d'argent. Le coût de la vie a une limite, même si personne ne daigne l'admettre. Les riches n'y sont pas tenus; ils pourront organiser en privé leur sortie de scène. Les autres sont doublement pénalisés, car on ne leur en donne ni l'autorisation ni les moyens.

"Quand il vit que son heure était venue», disent les contes pour enfants... Une issue aussi réglée et paisible est rare dans la vraie vie. Et les temps ont changé. Du point de vue d'alors, seules les sociétés opulentes vivaient comme dans un conte de fées. Les législateurs doivent, au moins dans nos pays, reconnaître le droit fondamental à l'euthanasie et porter leur attention sur les cas limites de personnes atteintes de maladies psychiques ou démentes et les risques d'abus manifestes. Les vaines guerres de tranchées sont un gaspillage d'énergie dont nous ne pouvons nous payer le luxe. Nous avons bien assez à faire. 